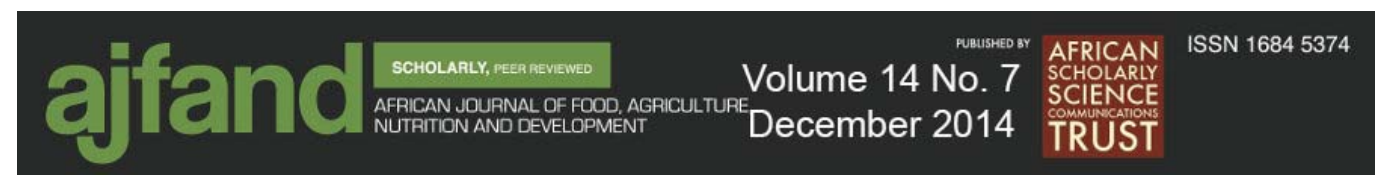

\title{
NUTRIENT COMPOSITION AND SUITABILITY OF FOUR COMMONLY USED LOCAL COMPLEMENTARY FOODS IN AKWA IBOM STATE, NIGERIA
}

Adepoju $\mathrm{OT}^{1 *}$ and AU Etukumoh ${ }^{1}$

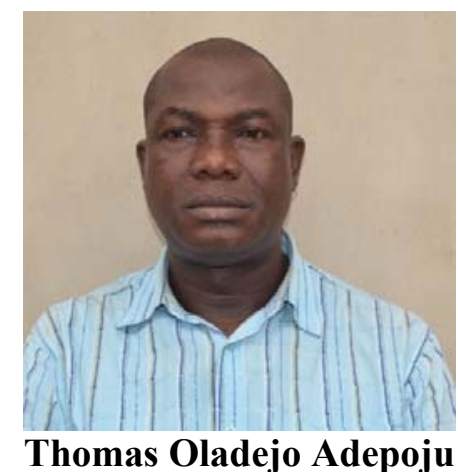

*Corresponding author email: tholadejo@yahoo.com

${ }^{1}$ Department of Human Nutrition, Faculty of Public Health, College of Medicine, University of Ibadan, Ibadan, Nigeria 


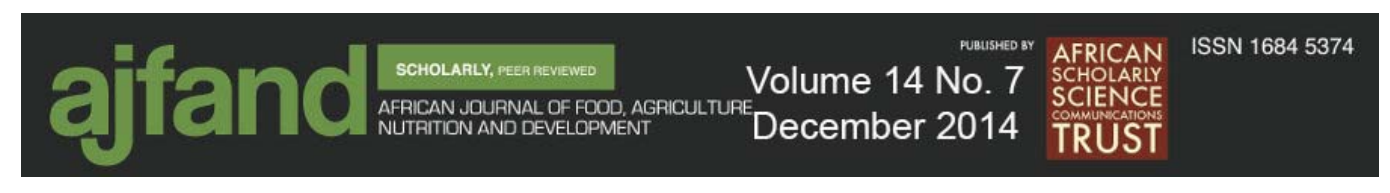

\begin{abstract}
Adequate nutrition is important during infancy and childhood where a short period of malnutrition has long lasting effects on growth, development and health in the adult life. The period from six months to two years constitutes a critical window of opportunity for promoting optimal growth, health and development, while insufficient quantity and quality of complementary foods (CFs), poor feeding practice and high rate of infection have a detrimental impact on growth in these important years. This study was designed to evaluate the nutrient composition and suitability of four commonly used complementary foods in two Local Government Areas (LGAs) of Akwa Ibom State, Nigeria. A descriptive cross-sectional survey involving women with children aged 6-24 months old was carried out in two randomly selected LGAs to identify the commonly used CFs. A total of 300 consenting mothers (150/LGA) aged 18 to 60 years presenting their children for immunisation in the two LGAs were respondents. A pretested, semi-structured questionnaire was used to obtain information on sociodemographic characteristics, knowledge on breastfeeding, complementary feeding practice, and types of CFs used from the respondents. Standardised samples of the four most commonly used CFs were prepared and analysed for nutrient and anti-nutrient composition using standard AOAC methods of analyses. Data were analysed using descriptive statistics and Chi square test, with level of significance set at $p=0.05$. Two types of unripe banana porridge, one mashed bean porridge, and mixed cereal pap with crayfish and 'turn brown' (soybean flour, groundnut and crayfish) were the four most commonly used CFs. One hundred grams portion of the CFs contained between 2.52 $6.70 \mathrm{~g}$ crude protein, $1.26-7.23 \mathrm{~g}$ crude lipid, 8.16 - $13.97 \mathrm{~g}$ carbohydrates and yielded up to $415.57 \mathrm{kcal}$ of energy. The mineral content ranged between $31.58-230.40 \mathrm{mg}$ potassium, 46.78 - $184.68 \mathrm{mg}$ calcium, 55.23 - $120.93 \mathrm{mg}$ phosphorus, 10.37 - 23.26 $\mathrm{mg}$ iron, $7.53-18.53 \mathrm{mg}$ of zinc / $100 \mathrm{~g}$ portion. The four complementary foods were nutritionally adequate and were low in anti-nutrients (oxalates, phytates, trypsin inhibitors, saponins and tannins), hence there is little risk of malabsorption of available nutrients. Utilization of unripe banana and mixed cereals with turn brown for infants provides cheap CFs with adequate energy and nutrients, and promotes biodiversity.
\end{abstract}

Key words: Nutrients, Complementary foods, Banana, Cereal, Beans 


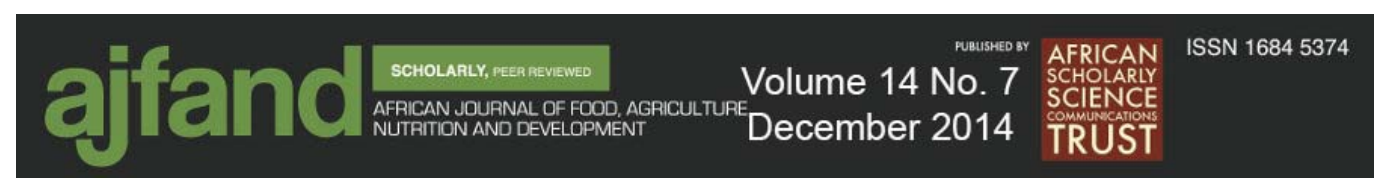

\section{INTRODUCTION}

Adequate infant nutrition is important during infancy and childhood, and the World Health Organization recommends exclusive breastfeeding till six months of age, and continued breastfeeding for at least two years along with timely introduction of adequate amount of complementary foods (CFs) of suitable nutritional quality [1]. Childhood malnutrition remains a public health challenge as the underlying cause of morbidity and mortality. In Nigeria, the Food Consumption and Nutrition Survey conducted in 2004 under Nigeria Health and Demographic Survey revealed that four out of every ten children are stunted as a result of poor diet and disease, one out of every four are underweight, while $9 \%$ are wasted [2].

The period from six months of age to two years constitute a critical window of opportunity for promoting optimal growth, health and development, while insufficient quantity and quality of CFs, poor feeding practice and high rate of infection have a detrimental impact on growth in these important years [3]. The major causes of malnutrition in young children have been attributed to poor quality of CFs and inappropriate feeding practices $[1,4]$. In Nigeria, the first CF is usually a thin cereal porridge made from fermented maize, millet, or sorghum $[5,6,7]$. This porridge provides $20-26 \mathrm{kcal} / \mathrm{kg}$ body weight/day, leading to a Nigerian infant having an average energy density of $0.26 \mathrm{kcal} / \mathrm{g}$ of CFs [8].

Appropriate complementary feeding involves timely introduction of food when the need for energy and nutrients exceed what can be provided through exclusive and frequent breastfeeding. CFs should be rich in energy and nutrients, clean and safe, easy to prepare from family foods, locally available and affordable. Most foods developed in the different countries to provide nutrient dense complementary foods to meet the nutritional needs of infants and young children are based on local foodstuffs blended with legumes to give protein portion of the diet [9]. Several types of commercial CFs marketed in many countries including Nigeria are nutritious but expensive for most Nigerian families, hence, mothers in both rural and urban areas depend on readily available, low-cost food mixtures to feed their infants.

Several strategies may be used to improve the nutritive value of CFs. The traditional West African CFs could be improved by combining locally available foods that complement each other in such a way that the new pattern of amino acids created by this combination is similar to that recommended for infants [1]. Documented information on types of CFs used by mothers in Akwa Ibom State are few [10], with no consideration of their nutrient content and suitability or otherwise. This study was therefore, designed to evaluate the nutrient composition and suitability of four most commonly used CFs in two selected Local Government Areas (LGAs) of Akwa Ibom State, Nigeria. 


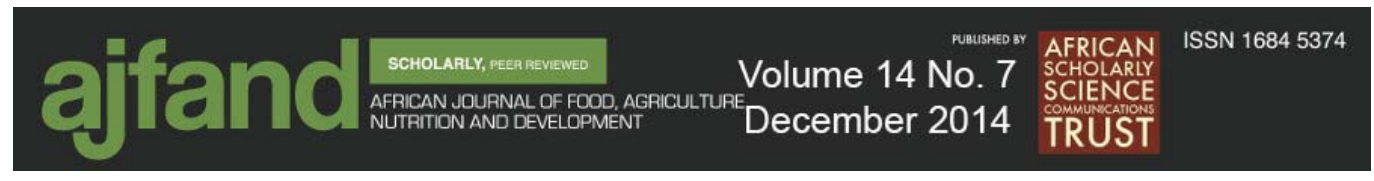

\section{MATERIALS AND METHODS}

\section{Sample Selection and Preparation}

Using a pre-tested, semi-structured interviewer-administered questionnaire, a descriptive cross-sectional survey involving women with children aged 6-24 months was carried out in two randomly selected LGAs of Uyo (Urban) and Uruan (Rural)) Areas of Akwa Ibom State to identify the four most commonly used CFs. The materials for preparing the four identified CFs were then purchased. Unripe banana (Musa sapientum), pumpkin leaf (Telferia occidentales), bonga fish (Ethmalosa fimbriata) (Figures 1A, 1B and 1C, respectively), maize (Zea mays L.), millet (Pennisetum americanum), guinea corn (Sorghum spp), crayfish (Macrobrachium spp), cowpea (Vigna unguiculata), groundnut (Arachis hypogea), soybean flour (Glycine max), palm oil (Elaeis guineensis), cow biscuit bone, salt and maggi were purchased from Akpan Andem market, Uyo, Akwa Ibom State and Bodija market, Ibadan, Oyo state, Nigeria. The mode of preparation obtained from the mothers on the field were standardised in the preparation of the four complementary foods as follows.

\section{Unripe Banana Porridge}

The unripe banana fingers ( $5 \mathrm{~kg}$ as purchased) were washed with distilled water, peeled, and the edible portion grated and divided into two parts. The first part $(1 \mathrm{~kg})$ was cooked into porridge with $50 \mathrm{~g}$ stock from cow biscuit bone, one cube of magi, $30 \mathrm{ml}$ palm oil, $100 \mathrm{~g}$ crayfish and $50 \mathrm{~g}$ pumpkin leaf and labelled as Sample 1, while the second part was cooked into porridge in the same way with dried Bonga fish, crayfish, maggi, palm oil and pumpkin leaf and labelled as Sample 2 (Figure 2).

\section{Mashed beans Porridge}

The Vigna unguiculata (white specie of cowpea) was cleaned by hand picking, washed with distilled water and the seed coat peeled off. After peeling the seed coat, the bean was cooked to a soft stage, and palm oil, maggi, salt and crayfish were added, cooked for a while and then mashed (Sample 3).

\section{Mixed Cereal Porridge}

Foreign materials and stones were picked from the maize, sorghum and millet. The cereals were mixed in the ratio 1:1:1, washed and steeped in water for 48 hours to ferment. The fermented mixture was milled, sieved and allowed to settle [11]. The resulting starch was used for the preparation of pap fortified with 'turn brown' formulated from soybean flour, crayfish and groundnut (Sample 4). A portion of the CFs was used for moisture determination while the remainder was oven dried at $60^{\circ} \mathrm{C}$ for eighteen hours and then subjected to chemical analysis.

\section{CHEMICAL ANALYSES}

\section{Proximate Composition}

The proximate composition of the complementary foods was determined using standard AOAC methods [12]. Moisture content of the four samples was determined by air oven method (Gallenkamp, Model OV - 440, England) at $105^{\circ} \mathrm{C}([12], 967.08)$. The crude 


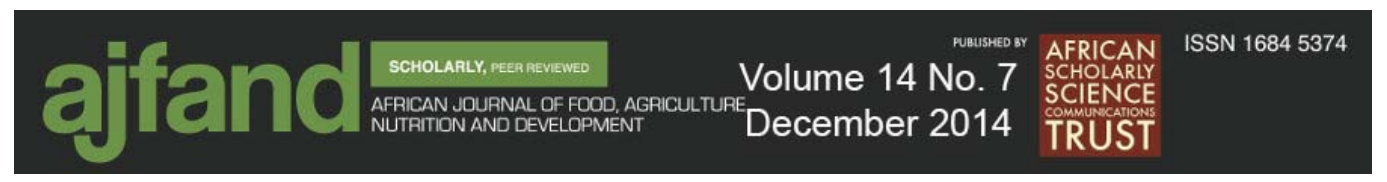

protein of the samples was determined using micro-Kjeldahl method (988.05), crude lipid was determined by Soxhlet extraction method (2003.06), while the ash content was determined by weighing $5 \mathrm{~g}$ of sample in triplicate and heated in a muffle furnace at $550^{\circ} \mathrm{C}$ for $4 \mathrm{~h}(942.05)$. Crude fibre was determined using the 958.06 method. The carbohydrate content was obtained by difference. Gross energy of the samples was determined using ballistic bomb calorimeter (Manufacturer: Cal 2k - Eco, TUV Rheinland Quality Services (Pty) Ltd, South Africa).

\section{Mineral analysis}

Potassium and sodium content of the samples were determined by digesting the sample ash with perchloric acid and nitric acid, and then taking the readings on Jenway digital flame photometer/spectronic20 [12]. Phosphorus was determined by the vanadomolybdate colorimetric method [12]. Calcium, magnesium, iron zinc, manganese and copper were determined spectrophotometrically by using Buck 200 atomic absorption spectrophotometer (Buck Scientific, Norwalk) and their absorption compared with absorption of standards [12].

\section{Vitamin Analysis}

\section{$\beta$-carotene Determination}

Vitamin A was determined through ultraviolet absorption measurement at $328 \mathrm{~nm}$ after extraction with chloroform. Calibration curve of vitamin A acetate was made and sample vitamin A concentration estimated as microgram $(\mu \mathrm{g})$ of vitamin A acetate.

\section{Thiamine (Vitamin $B_{1}$ ) Determination}

Thiamine content of the samples was determined by weighing $1 \mathrm{~g}$ of each sample into $100 \mathrm{ml}$ volumetric flask and adding $50 \mathrm{ml}$ of $0.1 \mathrm{M} \mathrm{H}_{2} \mathrm{SO}_{4}$ and boiled in a boiling water bath with frequent shaking for $30 \mathrm{~min} .5 \mathrm{ml}$ of $2.5 \mathrm{M}$ sodium acetate solution was added and flask set in cold water to cool contents below $50^{\circ} \mathrm{C}$. The flask was stoppered and kept at $45-50^{\circ} \mathrm{C}$ for 2 hours and thereafter made up to the $100 \mathrm{ml}$ mark. The mixture was filtered through a No. 42 Whatman filter paper, discarding the first $10 \mathrm{ml}$. Then 10 $\mathrm{ml}$ was pipetted from remaining filtrate into a $50 \mathrm{ml}$ volumetric flask and $5 \mathrm{ml}$ of acid potassium chloride solution was added with thorough shaking. Standard thiamine solutions were prepared and treated same way. The absorbance of the sample as well as that of the standards was read on a UV Spectrophotometer (Cecil A20 Model) at a wavelength of $285 \mathrm{~nm}$.

\section{Riboflavin (Vitamin $B_{2}$ ) Determination}

One gram of each sample was weighed into a $250 \mathrm{ml}$ volumetric flask, with $5 \mathrm{ml}$ of 1 $\mathrm{M} \mathrm{HCl}$ added, followed by addition of $5 \mathrm{ml}$ of dichloroethene. The mixture was shaken and $90 \mathrm{ml}$ of de-ionized water was added. The whole mixture was thoroughly shaken and was heated on a steam bath for $30 \mathrm{~min}$ to extract all the riboflavin. The mixture was then cooled and made up to volume with de-ionized water. It was then filtered, discarding the first $20 \mathrm{ml}$ of the aliquot. A $2 \mathrm{ml}$ aliquot of the filtrate was pipetted into another $250 \mathrm{ml}$ volumetric flask and made up to mark with de-ionized water. Sample was read on the spectrophotometer at a wavelength of $460 \mathrm{~nm}$. Standard solutions of 


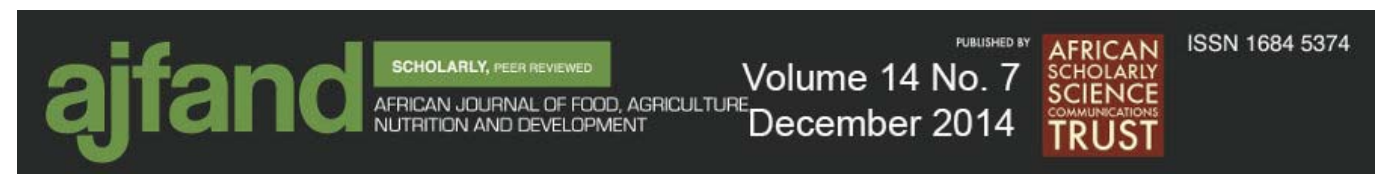

riboflavin were prepared and readings taken at $460 \mathrm{~nm}$, and the sample riboflavin obtained through calculation.

\section{Niacin (Vitamin $B_{3}$ ) Determination}

Five grams of blended sample was extracted with $100 \mathrm{ml}$ of distilled water. Then $5 \mathrm{ml}$ of this solution was drawn into $100 \mathrm{ml}$ volumetric flask and made up to the mark with distilled water. Standard solutions of niacin were prepared and absorbance of sample and standard solutions were measured at a wavelength of $385 \mathrm{~nm}$ on a spectrophotometer and niacin concentration of the sample estimated.

\section{Vitamin C (Ascorbic Acid) Determination}

Ascorbic acid in the sample was determined by titrating its aqueous extract with solution of 2,6-dichlorophenol-indophenol dye to a faint pink end point.

\section{ANTI-NUTRIENT ANALYSIS}

Oxalate was determined by extraction of the samples with water for about 3 hours and standard solutions of oxalic acid prepared and read on spectrophotometer (Spectronic20) at $420 \mathrm{~nm}$. The absorbance of the samples was also read and amount of oxalate estimated. Phytate was determined by titration with ferric chloride solution [13], while trypsin inhibitory activity was determined on casein and comparing the absorbance with that of trypsin standard solutions read at $280 \mathrm{~nm}$ [14]. The tannin content was determined by extracting the samples with a mixture of acetone and acetic acid for 5 hours, measuring their absorbance and comparing the absorbance of the sample extracts with the absorbance of standard solutions of tannic acid at $500 \mathrm{~nm}$ on spectronic20 [15]. Saponin was also determined by comparing the absorbance of the sample extracts with that of the standard at $380 \mathrm{~nm}$ [14].

\section{RESULTS}

\section{Proximate Composition}

The proximate composition of the four standardised CFs is shown in Table 1. The moisture content of the CFs was very high. There was no significant difference in the moisture content of Samples 1 and $2(p>0.05)$, but their values are significantly higher than that of Sample 3 and significantly lower than the value for sample $4(p<0.05)$. All the CFs were low in crude protein with significantly different values, sample 4 having the lowest value and sample 3 having the highest. No significant difference existed in the crude lipid values of samples 1 and $2(p>0.05)$, but they were significantly different from that of samples 3 and $4(\mathrm{p}<0.05)$. The crude lipid content of sample 3 was significantly higher than that of other samples, with sample 4 having the lowest value. Sample 4 had the lowest value for crude fibre, ash and carbohydrate, while sample 3 was highest in these parameters, with samples 1 and 2 having no significant difference in their values. 


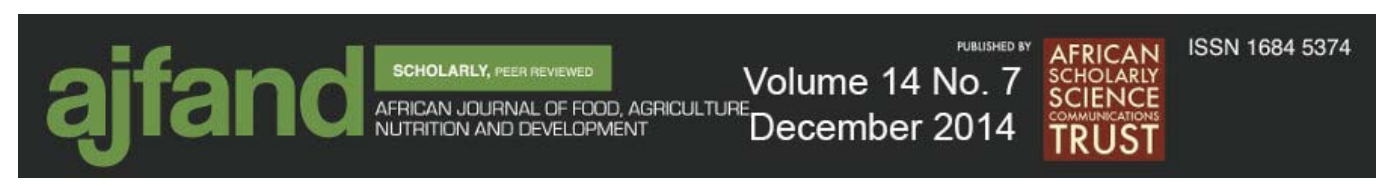

\section{Mineral Composition}

Samples 1 and 2 were high in all the minerals determined, with sample 1 having highest value for all the minerals (Table 2). Sample 3 had the lowest value of potassium and sodium, while sample 4 had lowest value in all other minerals. The mineral content of all the samples were significantly different from each other, with that of samples 1 and 2 being significantly higher $(\mathrm{p}<0.05)$.

\section{Vitamin Composition}

The values obtained for the vitamins in the CFs were significantly different from each other $(\mathrm{p}<0.05)$, and they were all very high in vitamin A content (Table 3$)$. Significant differences existed in the values of vitamin A for all the four samples $(p<0.05)$, with sample 3 having the highest while sample 4 had the lowest value. Samples 1 and 2 were high in thiamine and niacin, while all the complementary foods were low in riboflavin and ascorbic acid.

\section{Anti-nutrients}

The standardised CFs were very low in anti-nutrients (Table 4). Tannins and trypsin inhibitors were undetected at milligram level in Samples 1 and 2 while phytates and saponins were present at trace levels in the two samples. Sample 1 had the highest value of oxalates, sample 2 was highest in phytate content while sample 4 was highest in trypsin inhibitors. There were significant differences in values of the anti-nutrients in the complementary foods $(\mathrm{p}<0.05)$.

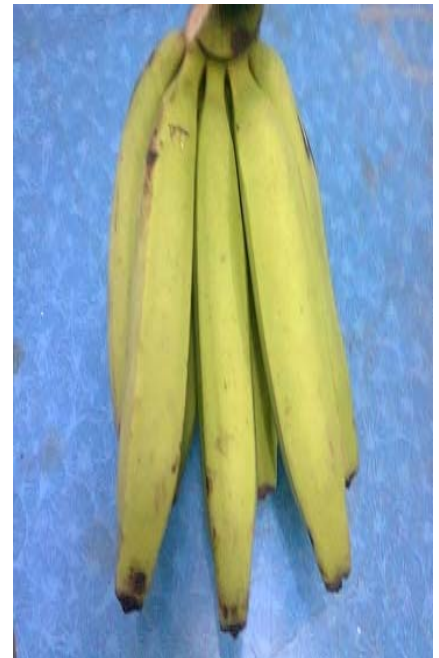

Figure 1:

(A) Banana fingers

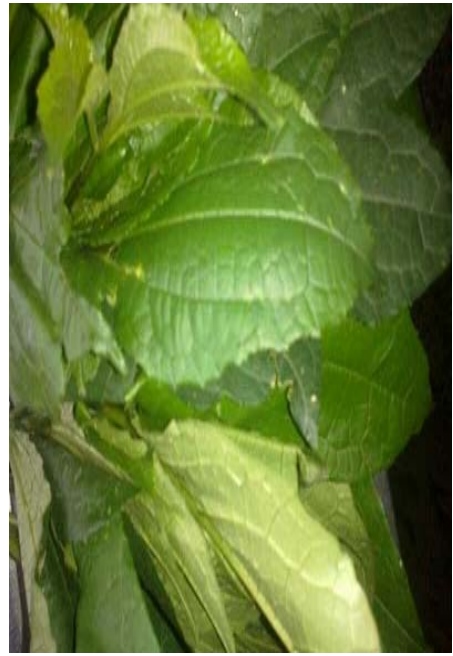

(B) Pumpkin leaf (Ugwu

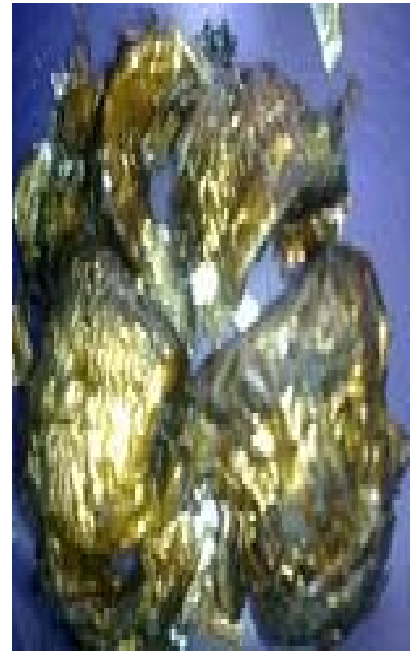

(C) Bonga fish 

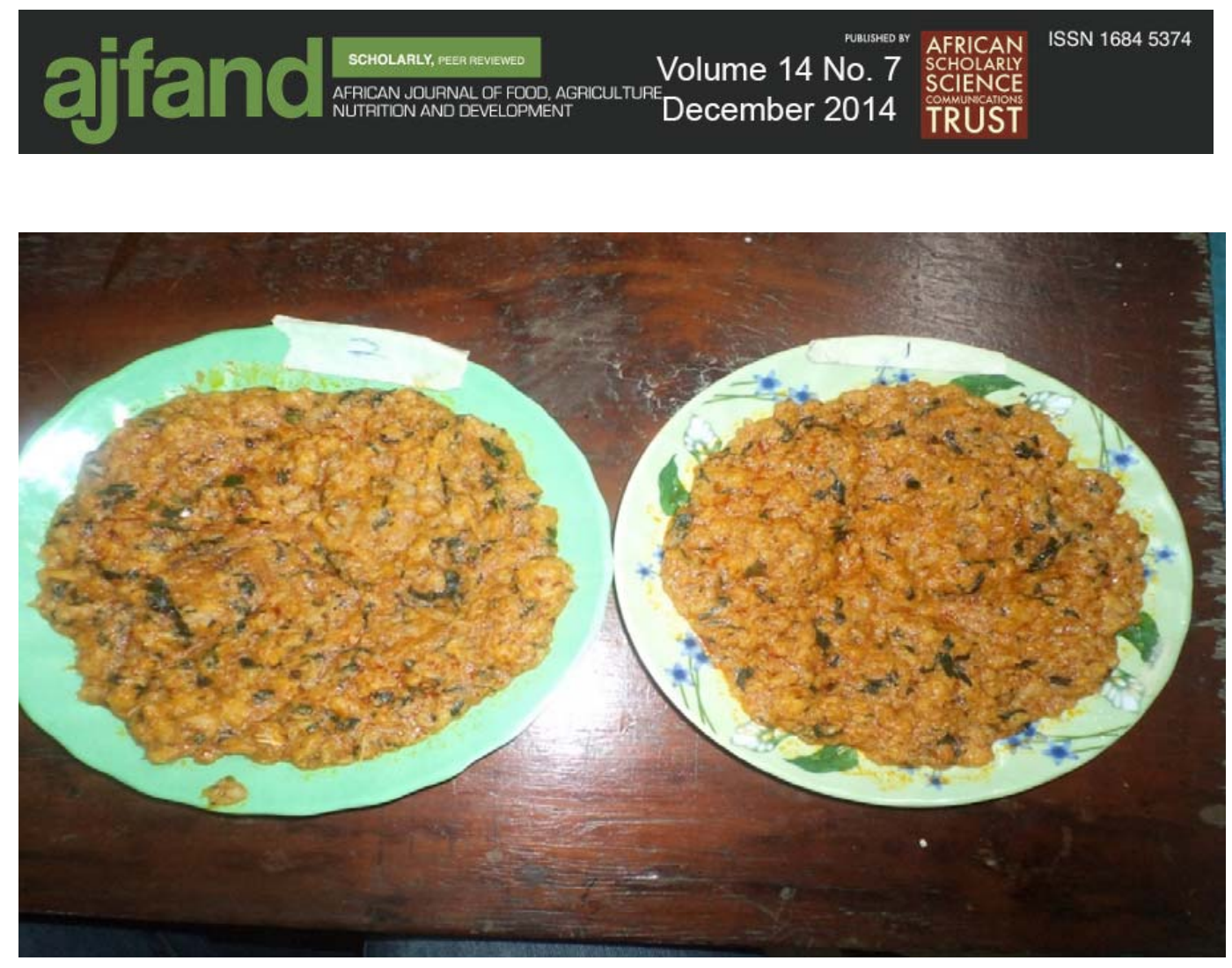

Figure 2: Prepared unripe Banana Porridge (Samples 1 and 2)

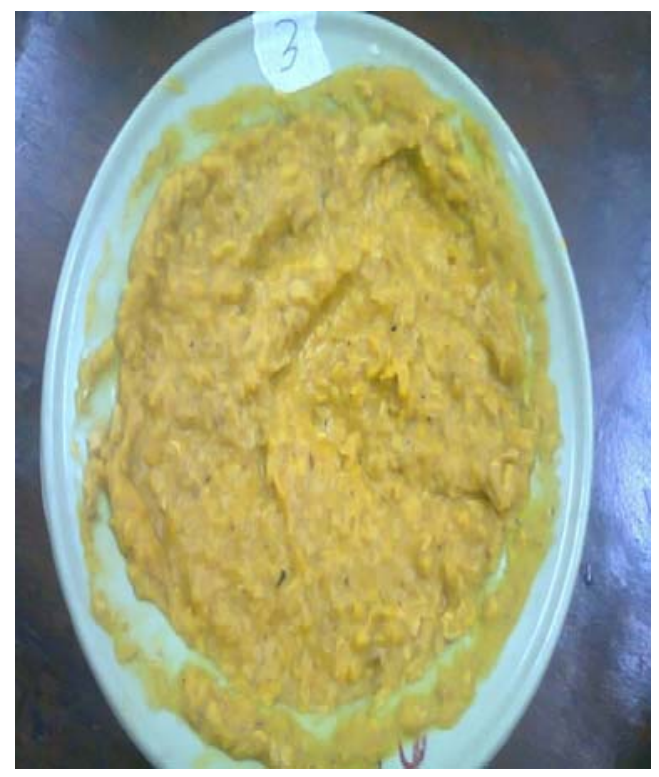

Figure 3: Mashed bean porridge (Sample 3)

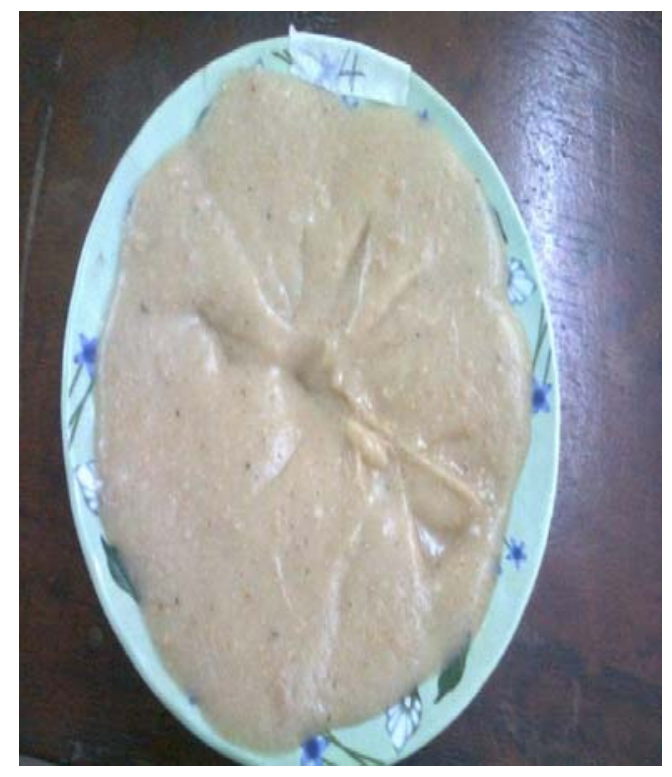

Figure 4: Mixed cereal Pap (Sample 4) 


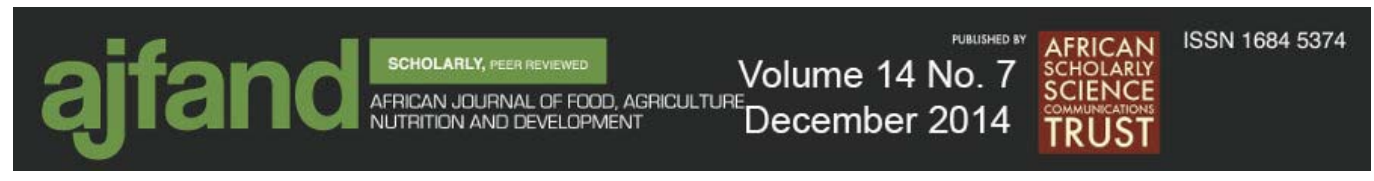

\section{DISCUSSION}

The values obtained for the proximate composition of the four complementary foods was in close agreement with reports of earlier works on CFs [16, 17, 18, 19]. All the formulated CFs were high in moisture content (Table 1). This was desirable, as the old infant is expected to be introduced into family foods in a semi-solid form to enable easy digestion and absorption of the foods as recommended for consistency of CFs $[1,20]$. The very high moisture content is indicative of low solid matter in the CFs.

High moisture content in foods has been shown to encourage microbial growth and easy spoilage [21]. This important fact has to be given serious consideration in the preparation of CFs because most mothers often prepare them in large quantity and store them in containers as means of preservation to avoid frequent processing. Preparing these CFs in the quantity that can be easily consumed over a period of time will ensure safety and protect the foods from microbial spoilage while preventing the child from diarrhoea and other infections.

Sample 3 had highest protein value, followed by samples 1 and 2, while sample 4 had the lowest value. This observed results can be explained bearing in mind that Vigna ungucuilata is a family of cowpea known as good source of plant protein, while cereals are poor sources of protein. Also soaking or fermentation has been reported to lead to loss of nutrients $[22,23]$, and this might have accounted for the low protein content of sample 4. Bananas and plantains are relatively higher in crude protein compared with cereals and grains, hence their relatively higher value than sample 4. Samples 3, 2 and 1 were significantly higher in crude lipid content than sample 4 . This is believed to be due to the added palm oil in the course of their preparation. Samples 3 and 4 were significantly lower in crude fibre compared with samples 1 and 2 . This was a direct result of peeling and sieving of the skin / husk of the basal materials (beans and the mixture of cereals), which contained more fibre than the endosperm. The high ash content of the standardized CFs is an indication of possible presence of minerals in high quantity, especially the macro minerals. Similar ash contents have been reported by other workers using crayfish in their respective formulations [16, 24, 25, 26].

Samples 1 and 2 formulated from banana were higher in mineral content than samples 3 and 4 (Table 2). The two samples were very high in iron, zinc and manganese, and moderately high in sodium, potassium, calcium, phosphorus, magnesium and copper. The high values of these minerals in the two complementary foods are expected, as the basal ingredient (banana) is a fruit with addition of pumpkin leaf. Fruits and vegetables are good sources of minerals and vitamins $[27,28]$. The mineral content of the two samples (samples 1 and 2) were significantly different from each other $(\mathrm{p}<0.05)$, sample 1 being higher in value. The observed variation in the mineral composition of samples 1 and 2 was an indication that cow biscuit bone was a richer source of minerals when compared to bonga fish. The observed lower mineral content of samples 3 and 4 is an indication that both cow biscuit bone and bonga fish contributed immensely to the mineral content of the CFs, and their minerals may be more readily available than that of plant origin. The lowest value of mineral content recorded for sample 4 might have 


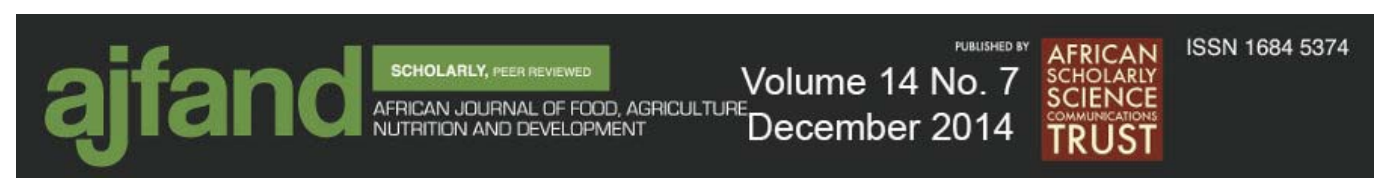

resulted from the fact that the grains were soaked, grinded and sieved, leading to loss of some of their mineral content. Soaking in water and sieving has been found to lead to leaching of the minerals into the water, or loss through husk removal [23, 29].

Lack of sufficient micronutrients in the diet affects the health and development of children and results in potential life-threatening deficiency diseases such as anemia and growth faltering, while zinc deficiency may negatively affect the behavioral development and growth of infants [27, 28]. The iron requirement in relation to energy intake of the rapidly growing infant is of utmost importance, hence, the need to rely on dietary iron. The iron and zinc content of the four CFs coupled with their level of calcium and phosphorus qualify them as nutrient-dense suitable foods.

The four CFs were very high in $\beta$-carotene (Table 3). The samples in which palm oil was used in their preparation contained higher $\beta$-carotene level (samples 1, 2, and 3) when compared with the one without palm oil (sample 4). Sample 3 had the highest value of $\beta$-carotene, followed by samples 2 and 1, respectively; while sample 4 was the lowest. All the samples differed significantly in their level of $\beta$-carotene $(p<0.05)$. Vitamin A is an important micronutrient, and its deficiency is of public health concern worldwide. Various interventional programmes embarked upon to eradicate or reduce its menace include food fortification, bio-fortification with $\beta$-carotene, and direct supplementation for children under-five years. If bio-available, the level of $\beta$-carotene in these CFs is adequate for infants and young children in the absence of worm infestation.

The level of water soluble vitamins in the CFs is adequate for infants and young children to meet their nutritional needs, and samples 1 and 2 which are fruit-based are higher in these vitamins than samples 3 and 4 which had undergone one processing or the other before being used in food formulation. The various processes to which the ingredients had been subjected to led to loss of the water soluble vitamins in samples 3 and 4.

The highest value of phytate was observed in sample 3, sample 1 was highest in oxalate, while sample 4 was highest in trypsin inhibitors (Table 4). Tannins and trypsin inhibitors were not detectable at milligramme level in samples 1 and 2. All the four samples were very low in anti-nutrients studied (Table 4). The presence of anti-nutrients such as phytates and tannins in foods has been reported to reduce bioavailability of important nutrients in human nutrition [14]. The phytates, saponins and tannins content of the preparations were insignificantly low that they cannot constitute or hinder bioavailability of any nutrient. 


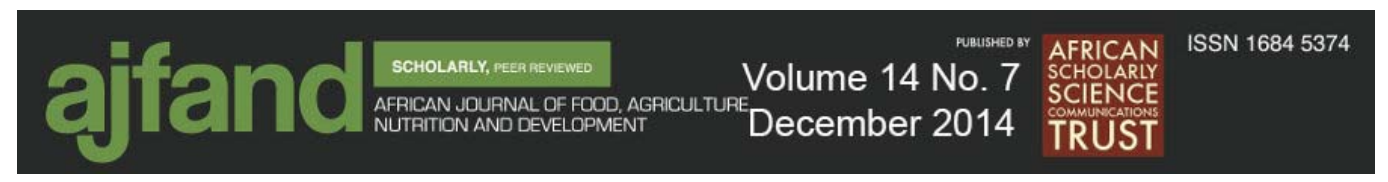

\section{CONCLUSION}

All the standardized locally formulated CFs contained essential nutrients and their metabolisable energy can meet the daily energy requirement of infants aged 611 months. They contain essential minerals needed for growth and development in adequate amounts, and had low levels of anti-nutrients. CFs formulated with banana seemed to be more nutritious and nourishing, containing all the required nutrients, very low in anti-nutrients, cost effective and easy to prepare. Utilization of unripe banana porridge, mixed cereals with turn brown and proper preparation of beans for infants can provide cheap CFs that are high in protein and energy, and nutrient-dense to meet the nutritional needs of infants and young children. Hence their use should be encouraged as a means of promoting dietary diversity and reducing prevalence of under-five malnutrition in Nigeria. 


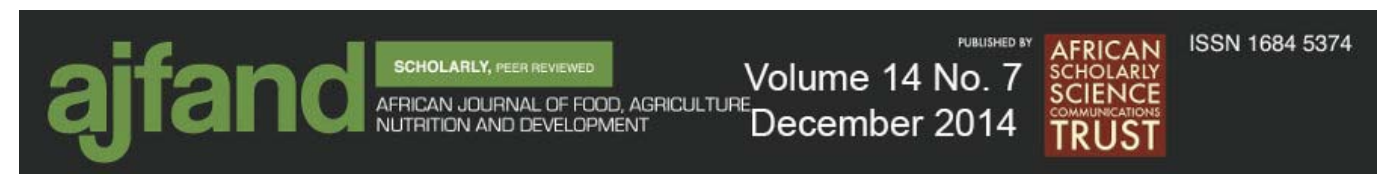

Table 1: Proximate composition of standardised complementary foods (g/100g Fresh meal)*

Sample

$1 \quad 2 \quad 3 \quad 4$

Moisture $78.01 \pm 0.02^{\mathrm{a}} \quad 78.52 \pm 0.02^{\mathrm{a}}$

$68.59 \pm 0.04^{\mathrm{b}} \quad 86.85 \pm 0.03^{\mathrm{c}}$

Crude Protein $4.21 \pm 0.13^{\mathrm{a}}$

$4.39 \pm 0.18^{\mathrm{b}}$

$6.70 \pm 0.11^{\mathrm{c}}$

$2.52 \pm 0.09^{\mathrm{d}}$

Crude Lipid

$3.72 \pm 0.03^{\mathrm{a}}$

$3.76 \pm 0.03^{\mathrm{a}}$

$7.23 \pm 0.03^{\mathrm{b}}$

$1.26 \pm 0.04^{\mathrm{c}}$

Crude Fibre

$0.64 \pm 0.02^{\mathrm{a}}$

$0.64 \pm 0.04^{\mathrm{a}}$

$0.23 \pm 0.03^{\mathrm{b}}$

$0.07 \pm 0.02^{\mathrm{c}}$

Ash $1.05 \pm 0.06^{\mathrm{a}}$

$1.06 \pm 0.58^{\mathrm{a}}$

$0.38 \pm 0.01^{\mathrm{b}}$

$0.34 \pm 0.06^{\mathrm{c}}$

Carbohydrate

$12.38 \pm 0.06^{\mathrm{a}}$

$11.63 \pm 0.06^{\mathrm{b}}$

$16.87 \pm 0.40^{\mathrm{c}}$

$8.96 \pm 0.16^{\mathrm{d}}$

**Metabolisable Energy (kcal/) $99.84 \pm 0.20^{\text {a }}$

$97.92 \pm 0.10^{\mathrm{a}}$

$159.35 \pm 0.39^{\mathrm{b}}$

$57.26 \pm 0.05^{\mathrm{c}}$

*Values are mean $\pm S D$ for three determinations.

Values with the same letter are not significantly different, while those with different letters are significantly different.

**Metabolisable energy calculated as sum of crude protein $x 4$, crude lipid $x 9$ and carbohydrate $\times 4$

Sample 1 = Banana porridge with biscuit bone, crayfish, magi, palm oil and pumpkin leaf

Sample 2 = Banana porridge with bonga fish, crayfish, magi, palm oil and pumpkin leaf Sample 3 = Mashed beans, crayfish, palm oil, magi and salt

Sample 4 = Mixed cereals and "Turn brown" (Soybean flour, groundnut and crayfish) 


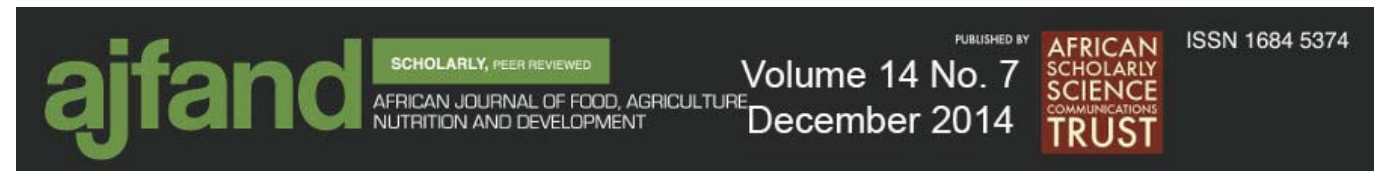

Table 2: Mineral composition of standardised complementary foods (mg/100g

Sample Fresh meal)*

$\begin{array}{lrrrr}\text { Sodium } & 161.25 \pm 0.57^{\mathrm{a}} & 151.01 \pm 0.06^{\mathrm{b}} & 31.71 \pm 0.07^{\mathrm{c}} & 47.10 \pm 0.03^{\mathrm{d}} \\ \text { Potassium } & 230.40 \pm 0.03^{\mathrm{a}} & 205.20 \pm 0.05^{\mathrm{b}} & 31.58 \pm 0.27^{\mathrm{c}} & 96.68 \pm 0.08^{\mathrm{d}} \\ \text { Calcium } & 184.68 \pm 0.50^{\mathrm{a}} & 160.63 \pm 0.04^{\mathrm{b}} & 63.59 \pm 0.20^{\mathrm{c}} & 46.78 \pm 0.02^{\mathrm{d}} \\ \text { Magnesium } & 81.72 \pm 0.04^{\mathrm{a}} & 67.87 \pm 1.51^{\mathrm{b}} & 69.93 \pm 0.10^{\mathrm{c}} & 44.79 \pm 0.03^{\mathrm{d}} \\ \text { Phosphorus } & 120.93 \pm 0.05^{\mathrm{a}} & 114.82 \pm 0.06^{\mathrm{b}} & 89.15 \pm 0.11^{\mathrm{c}} & 55.23 \pm 0.57^{\mathrm{d}} \\ \text { Iron } & 23.26 \pm 0.12^{\mathrm{a}} & 21.37 \pm 0.04^{\mathrm{b}} & 20.83 \pm 0.91^{\mathrm{c}} & 10.37 \pm 0.28^{\mathrm{d}} \\ \text { Zinc } & 18.53 \pm 0.04^{\mathrm{a}} & 16.00 \pm 0.05^{\mathrm{b}} & 14.05 \pm 0.09^{\mathrm{c}} & 7.53 \pm 0.03^{\mathrm{d}} \\ \text { Manganese } & 13.29 \pm 0.04^{\mathrm{a}} & 12.16 \pm 0.03^{\mathrm{b}} & 11.43 \pm 0.07^{\mathrm{c}} & 7.02 \pm 0.05^{\mathrm{d}} \\ \text { Copper } & 2.59 \pm 0.21^{\mathrm{a}} & 2.47 \pm 0.14^{\mathrm{b}} & 3.22 \pm 0.21^{\mathrm{c}} & 0.88 \pm 0.21^{\mathrm{d}}\end{array}$

*Values are mean $\pm S D$ for three determinations

Values with different letters are significantly different

Table 3: Selected vitamin composition of standardised complementary foods (mg/100g)*

Sample 1 2 3 4

Vitamin A $(\mu \mathrm{g} /)$

$$
\begin{array}{r}
967.80 \pm 0.03^{\mathrm{a}} \\
1.69 \pm 0.03^{\mathrm{a}} \\
0.55 \pm 0.03^{\mathrm{a}} \\
8.69 \pm 0.02^{\mathrm{a}}
\end{array}
$$$$
979.85 \pm 1.50^{b}
$$$$
1218.21 \pm 0.04
$$$$
654.31 \pm 0.03^{\mathrm{d}}
$$

Thiamine$$
2.23 \pm 0.02^{b}
$$$$
0.85 \pm 0.04^{\mathrm{c}}
$$

$0.71 \pm 0.02^{d}$

Riboflavin

$$
0.64 \pm 0.03^{b}
$$

$0.29 \pm 0.02^{\mathrm{c}}$

$0.44 \pm 0.03^{\mathrm{d}}$

Niacin

$$
9.09 \pm 0.03^{b}
$$

$1.89 \pm 0.04^{\mathrm{c}}$ $2.00 \pm 0.04^{\mathrm{d}}$

Ascorbic acid

$$
13.70 \pm 0.04^{\mathrm{a}}
$$

$12.53 \pm 0.03^{b}$

$9.38 \pm 0.03^{\mathrm{c}}$

$8.95 \pm 1.15^{\mathrm{d}}$

*Values are mean $\pm S D$ for three determinations

Values with different letters are significantly different 


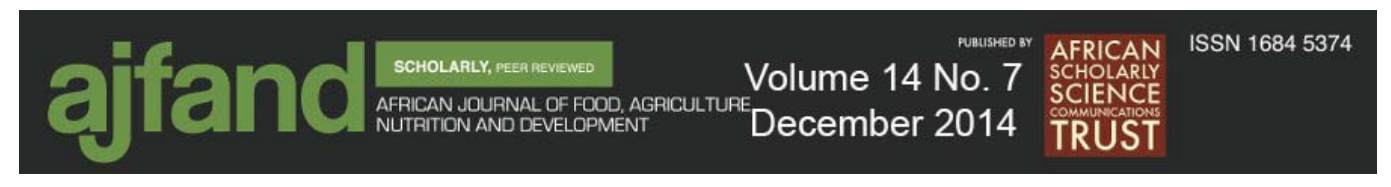

Table 4: Anti-nutrient content of standardised complementary food samples (mg/100g)*

Sample 1

Phytates

$$
0.01 \pm 0.00^{\mathrm{a}} \quad 0.01 \pm 0.00^{\mathrm{a}}
$$

3

4

Oxalates

$$
0.24 \pm 0.00^{\text {a }} \quad 0.04 \pm 0.00^{\text {b }}
$$

$0.10 \pm 0.00^{\mathrm{b}}$

$0.01 \pm 0.00^{\mathrm{a}}$

Tannins

$$
0.00 \pm 0.00^{\mathrm{a}}
$$

$0.00 \pm 0.00^{\mathrm{a}}$

$0.10 \pm 0.00^{\mathrm{c}}$

$0.12 \pm 0.00^{\mathrm{d}}$

Saponins

$$
0.01 \pm 0.00^{\mathrm{a}}
$$

$0.01 \pm 0.00^{\mathrm{a}}$

$0.01 \pm 0.00^{\mathrm{b}}$

$0.01 \pm 0.00^{\mathrm{b}}$

Trypsin inhibitors

$$
0.00 \pm 0.00^{\mathrm{a}}
$$

$0.00 \pm 0.00^{\text {a }}$

$0.00 \pm 0.00^{\mathrm{b}}$

$0.10 \pm 0.00^{\mathrm{c}}$

*Values are mean $\pm S D$ for three determinations

Values with the same letters are not significantly different, while those with different letters are significantly different 


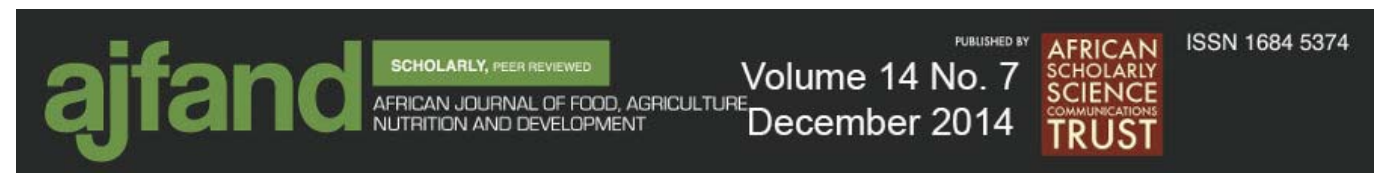

\section{REFERENCES}

1. WHO. Global strategy for Infant and young child feeding. WH/A55/2002/REC/1 Annex 2. Geneva. 2002.

2. NDHS. Nigeria Demographic and Health Survey. National Population Commission, Federal Republic of Nigeria Abuja, Nigeria. Measure DHS, ICF Macro Calverton, Maryland, USA 2008.

3. Shrimpton R, Victora CG and M de Onis Worldwide timing of growth faltering: implications for nutritional interventions. Pediatrics 2001; 107: E75.

4. Pelto GH, Levitt $\mathbf{E}$ and $\mathbf{L}$ Hairu Improving feeding practices: current patterns, common constraints, and the design of interventions. Food and Nutrition Bulletin. 2003; 24: 45-82.

5. Nnam NM Evaluation of complementary foods based on maize, groundnut, pawpaw and mango flour blends. Nigerian Journal of Nutritional Sciences 2002; 22 \& 23: 8-18.

6. Anigo KM, Ameh DA, Ibrahim S and SS Danbauchi Nutrient composition of complementary food gruels formulated from malted cereals, soybeans and groundnut for use in North-western Nigeria. African Journal of Food Science 2010; 4(3): 65-72.

7. Awogbenja MD and FU Ugwuona Feeding practices and nutritional status of under- five children in Nasarawa State, Nigeria. Retrieved from www. Patnsukjournal.net/currentissue 2010.cited 15/10/2012.

8. Brown KH, Dewey KG and LH Allen Complementary feeding of young children in developing countries: A review of current scientific knowledge. WHO/UNICEF 1998.

9. Lartey A, Manu A, Brown KH, Person JM and KG Dewey A randomized community based trial of the effect of improved centrally processed complementary foods on growth and micronutrient status of Ghanaian infants from 6 to 12 months of age. American Journal of Clinical Nutrition 1999; 7: 391-404.

10. Eka B, Essien B, Abeey $\mathbf{W}$ and JO Akaninwor Nutritive evaluation of some traditional weaning foods from Akwa Ibom State. Nigerian Journal of Biochemistry and Molecular Biology 2010; 25(1): 65-72.

11. Akinrele IA Biochemical study of traditional method of preparation of "Ogi" and its effects on the nutritive value of corn. Doctoral thesis 1966, University of Ibadan, Ibadan, Nigeria. 


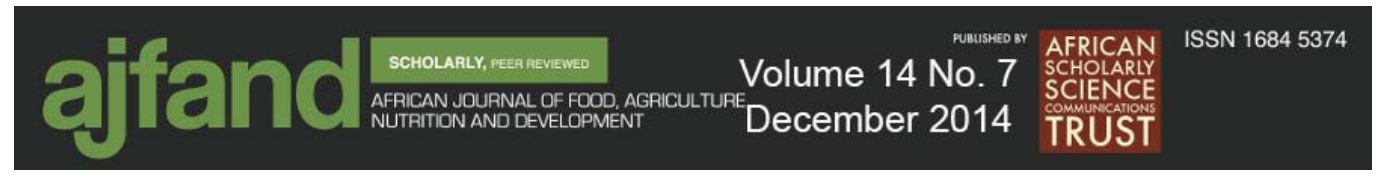

12. AOAC. Association of Official Analytical Chemists Official methods of Analysis of AOAC International, Gaithersburg, MD. USA, 2005.

13. Sudarmadji S and P Markakis The phytate and phytase of soybean Tempeh. Journal of Science of Food and Agriculture 1977; 28(4): 381-383

14. Makkar HP and K Becker Nutritional value and anti-nutritional components of whole and ethanol extracted Moringa oleifera leaves. Animal Feed Science and Technology 1996; 63: 211-228.

15. Griffiths DW and DIH Jones Cellulase inhibition by tannins in the testa of field beans (Vicia faba). Journal of Science of Food and Agriculture 1977; 28(11): 938-989.

16. Solomon M Nutritive value of three potential complementary foods based on cereals and legumes. African Journal of Food Agriculture 2005; 5(2).

17. Ijarotimi OS and AJ Olopade Determination of amino acid content and protein quality of complementary food produced from locally available food materials in Ondo State, Nigeria. Malaysian Journal of Nutrition 2009; 15(1): $87-95$.

18. Essien EB, Abeey BW and JO Akaninwor Nutritive evaluation of some traditional weaning foods from Akwa Ibom State. Nigerian Journal of Biochemistry and Molecular Biology, 2010; 25(1): 65-72.

19. Ikpeme-Emmanuel OE and GO Igile Chemical and protein quality of Soybean (Glycine max) and Tigernut (Cyperus esculentus) based weaning food. Journal of Food Research, 2012; 1(2): 246-254.

20. FMoH. Federal Ministry of Health national policy on infant and young child feeding in Nigeria, Abuja 2005.

21. Temple VJ, Badamosi EJ, Ladeji O and M Solomon Proximate Chemical Composition of three locally formulated complementary foods. West African journal of Biological Science 1996; 5: $134-143$.

22. Bradbury JH, Bradshaw K, Jealous W, Holloway WD and T Phimpisame Effect of cooking on nutrient content of tropical root crops from the South Pacific J Sci. Food Agric. 1998; 43: 333-342.

23. Adepoju OT, Adekola YG, Mustapha SO and SI Ogunola Effect of processing methods on nutrient retention and contribution of local diets from cassava (Manihot spp) to nutrient intake of Nigerian consumers. African Journal of Food Agriculture, Nutrition and Development (AJFAND) 2010; 10(2): 2099-2111. 


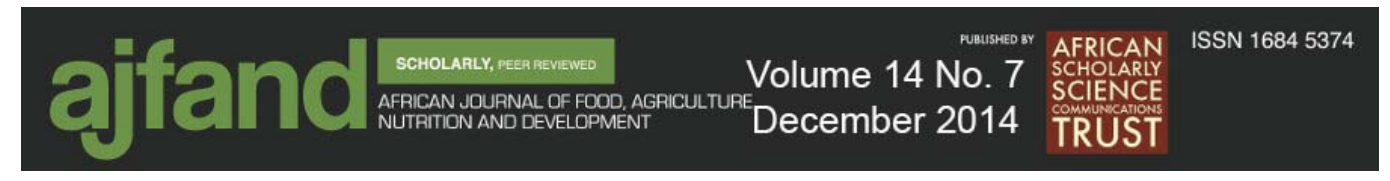

24. Abbey BW and UE Nkanga Production of High Quality Weaning Product Maize-cowpea- crayfish mixtures. Nutrition Reports International1988; 37(5): 951-957.

25. Onyeike EN and PI Morri Evaluation of the Nutritional quality of a weaning food from African yam bean - rice - prawn mixtures. Delta Agriculturist 1996; 33: $134-147$.

26. Samuel FO and BO Otegbayo Chemical analysis and sensory evaluation of Ogi enriched with Soybeans and Crayfish. Nutri Food Sci. 2006; 36(4): $214-$ 217.

27. Roth RA and CE Townsend Nutrition and Diet Therapy, ed 8. Clifton Park, Delmar, 2003; pp 221-223.

28. Rolfes SR, Pinna $\mathbf{K}$ and $\mathbf{E}$ Whitney Understanding normal and clinical nutrition. Eighth Edn Wadsworth Cengage Learning 2009; Pp383.

29. Adepoju OT, Sunday BE and OA Folaranmi Nutrient composition and contribution of plantain (Musa paradisiacea) products to dietary diversity of Nigerian consumers. African Journal of Biotechnology 2012; 11(71): 1360113605 . 